\title{
Locating the Livelihood Problems for the Promotion of Sustainable Life in Slums of Dehradun, Uttrakhand, India using IKONOS High Resolution Satellite Image
}

\author{
Swadesh Kumar $^{1 *}$, Venkatesh Dutta ${ }^{1}$, Sadhana Jain ${ }^{2}$ \\ ${ }^{I}$ Department of Environmental Sciences, Babashaheb Bhimrao Ambedker University, Lucknow-226025 \\ ${ }^{2}$ Urban and Regional Studies Department, Indian Institute of Remote Sensing (IIRS), Dehradun
}

\begin{abstract}
Smaller Settlements are important for sustainable housing; however, a large proportion of urban area is covered by squatter settlements and slums in Indian cities with poor housing facilities. Growth of such slum clusters is a major problem which is further exacerbated by increasing urban development and deficit of affordable housing. There are many challenges in the task of making cities free of slums and improve the situation in existing slums. Spatial mapping of such areas is an effective tool for the improvement of slums. In this study, an attempt has been made to study the slum settlements in Dehradun city with an objective to provide useful information on sustainable housing as well as help planners make appropriate interventions using remote sensing and GIS. The purpose of this study is to locate the livelihood problems for promotion of sustainable life in slums, households having roof material other than concrete, not having facility of drinking water; drainage and latrine are treated as slums as well as contiguous area with 20-25 households.
\end{abstract}

Key words: Squatter Settlements, Sustainable, Population, Slums, GIS

\section{Introduction}

The increasing population growth, unplanned urbanization, industrialization and migration of villagers to cities due to poverty creates the problem of squatter settlements in most of the big, medium, and small cities in India. The uncontrolled development of slums creates a lot of problems on civic infrastructure. According to Govt. of India's Ministry of Urban Development statistic, the estimated slum population of the country was 75.26 million in 2001 and world's slum population is estimated to reach 889 million by 2020 (UN-Habitat, 2010). Another major challenge is urbanization, with almost all of the expected 2 billion population increase by 2030 expected to occur in urban areas in currently developing countries (Pitcher, 2009). Moreover half of the population increase is estimated to be in urban slums, approximately doubling the size of slum population to 2 billion (Payne, 2005; UN-Habitat, 2008). Proper information about slums, land use, population growth, civic infrastructure, government service facilities, and many other useful records are not available in the municipal bodies. This creates many hurdles in implementation of development programs and problem identifications. In the recent years, Remote sensing (RS) and Geographical Information System (GIS) has developed new approaches which help us to analyze satellite data that provide necessary information. It also helps in locating and mapping of different livelihood problems. For sustainable development of squatter settlements, monitoring and mapping of slums is very critical to make effective policy for development of unplanned areas. But it can be help in monitoring and mapping of slums with reliable data at regular intervals (Rajeswari, 2006). Therefore, there is an urgent need to adopt RS-GIS techniques for promoting the sustainable life in slums. RS-GIS techniques helps us to analyses the data spatially, offering possibilities of generating various thematic maps with information related to poverty, primary schools, housing, unemployment, health services. World Health Organization (WHO) says, "Bad environmental quality is estimated to be directly in charge of $25 \%$ of preventable ill-health on earth nowadays, with diarrhoeal diseases and acute respiratory attacks" (WHO, 1998).

The concept of slums and their definition varies from country to country depending upon problems, condition and basic characteristics such as-housing structures, poor ventilation, acute over-crowding, scarcity of safe drinking water, water logging during rains, absence of sanitation facilities and non-availability of other basic civic services such as education, health and employment. Slums came to create an intrinsic part of the phenomena of urbanization in India. The slum expansion is as a result of pressure of the population primarily on un-used, unprotected, and un-suitable government land. In the absence of appropriate methods for housing issues, a number of metropolitan dwellers, public and private decision makers would not have the ability to meet up with the issues of sustainable urban development (Shekhar, 2012). Slums and unlisted slums are often located on land near drains, dumping grounds, roadsides or railway lines making them prone to a number of vulnerabilities like displacement, disease prone or accidents. Slums located adjacent to large open drains and it has a greater incidence of diarrhea and other water-borne diseases. Slums with inadequate housing are more 
Locating the Livelihood Problems for the Promotion of Sustainable Life in Slums of Dehradun,

likely to have worse health indicators. Improper housing in terms of lack of ventilation, overcrowding, lack of cleanliness, dampness leads to faster spread of many communicable diseases like measles and tuberculosis. Squatter settlements usually face constant threat of eviction. Unlisted slums are usually left out of slum improvement programs and have poor access to basic services. Being new habitations, unlisted slums have weaker social cohesion and poorer negotiating capacity to demand better services. Jain et al. (2005) studied the development pattern of informal settlements in Dehradun using IKONOS satellite data. It was found that most of the informal settlements are along natural drainage, due to better accessibility and job opportunities in the surrounding areas.

The objective of this research paper was to located the livelihood problems in slum around Rispana river of Dehradun city for their sustainable planning and management. Dehradun became the capital of Uttarakhand, a state carved out from Uttar Pradesh in the year 2000. The population of the city increased from 2.7 lakhs in 1991 to 4.48 lakhs in 2001. By 2011, the population of the city is expected to grow to 6.57 lakhs. The population of the city is expected to grow at $4 \%$ per annum till 2010 , after which the growth rate is expected to drop to $3.5 \%$ per annum till 2015. This high rate of growth in 2001-2011 decade is because of the city becoming the capital of the new state of Uttaranchal. State Urban Development Agency (SUDA) obtained information about 1,20,850 persons (i.e. 19,917 households) live in slums. Dehradun is a city which also famous for tourism and hence the tourist arrivals in the city have been increasing from 4.6 lakhs in 2000 to 9.3 lakhs in 2003. The floating population of the city is estimated at 35,000 persons per day.

\subsection{Focus on Earlier Slum Identification and Mapping}

According to Ujjawal et al. (2005) slums has increased from 75 in 1996 to 113 in 2000 . The total area under slum is now more than 279.65 acre. Out of the 113 slums of Dehradun city, nearly 90 slums are developed near the Bindal Rao and Rispana Rao rivers and covered a major part of river sides. This study also explored that 23 slums was away from the river side and have grown up near the railway station, railway line (that goes to Haridwar) and both side of major roads. Slum means any area with buildings is decaying and aged in condition. According to the Global Development research Centre (2003) slums area are the highly populated and congested urban areas marked by deteriorated unauthorized and insanitary buildings (UN-Habitat, 1982; 1987). Regarding the location of settlements Desai and Devadas (1990) have noted that slums are poorly provided with open spaces and recreational facilities, badly designed for sanitation, safety and other physical infrastructure and finally they are characterized by inadequate street.

In this section, we discuss three various slum mapping approaches these are census based approach, participatory approach and advanced remote sensing image analysis. The terms informal settlements and slums are utilized interchangeably, since informal settlements in many cases are known as slums in past literature (Hofmann, et al., 2008; UN-HABITAT, 2003b, p. 219). The census-based approach uses data collected through census surveys as a schedule of deprivations/poverty mapping. Census data contain information on the inhabitants residing in a country aggregated to little areas to safeguard specific privacy. They include data on social, financial and habitat/infrastructural aspects at the particular level of an enumeration device (Baud et al., 2008; Kohli et al., 2011). As census data are routinely collected in many countries, they provide an interesting option for poverty/slum mapping. The participatory approaches require mapping the details of everyday settlements at individual or household stage with the cooperation of slum-dwellers (Joshi et al., 2002). Hasan (2006) used this approach to study and map infrastructure details of everyday settlements in Karachi. Karanja (2010) presented a full enumeration of homes and slums in Kisumu, Kenya. Participatory approaches can help to create spatial and non-spatial information in the shape of thematic GIS layers that offer a supplement to socio-economic surveys and feed into slum-related policy growth and planning. Advance Remote Sensing based approach uses image processing practices to map slums from satellite imagery. Remote Sensing provides spatially disaggregated information with high temporal uniformity that may help quick monitoring and successful intervention of slums by local authorities. Jain et al. $(2005 ; 2007)$ proposed the image processing for digital classification and also described the change in slum patterns over time and space.

\subsection{Study Area}

\section{Material and Method}

The study area was located in the southern part of Dehradun district (lying between $78^{\circ} \mathrm{E}$ to $78^{\circ} 10^{\prime}$ and $30^{\circ} 15^{\prime} \mathrm{N}$ to $30^{\circ} 25^{\prime} \mathrm{N}$ ), with a total population of 1,030,720, as per Census of India 2001. On this figure, 195,604 people are living in slums, which was $18.98 \%$ of the total population. The city located at an altitude of $640 \mathrm{Mt}$. above mean sea level slopes gently from north to south and southwest with a gradient of 1:37.5. The city is highly dissected by a number of streams, which are locally known as Khalas. The drainage of the city is born by Bindal and Rispana river. 
The identification of slum areas of Dehradun city helps to changing in slums and their environment with good housing and availability of different necessary sources. These problematic challenges were expressed by different international initiatives for improving the living conditions of slum dwellers all over the world. For the improving of slums, this was initiated by Alliance campaign "Cities without Slums" in 1999. It's Millennium Development Goals (MDGs) is to "Ensure Environmental Sustainability" and "To improve the lives of at least 100 million slum dwellers by 2020" (United Nations, 2007: 25). The study has been carried out in Sanjay Colony, Bhagat Singh Colony, Shivpuri Colony, Purani Basti, Inder Road, Pritam Road and Mohini Road of the Dehradun city (fig.1). These colonies are situated along the Rispana Rao River, which is one of the main seasonal drains towards the north eastern part of the city.

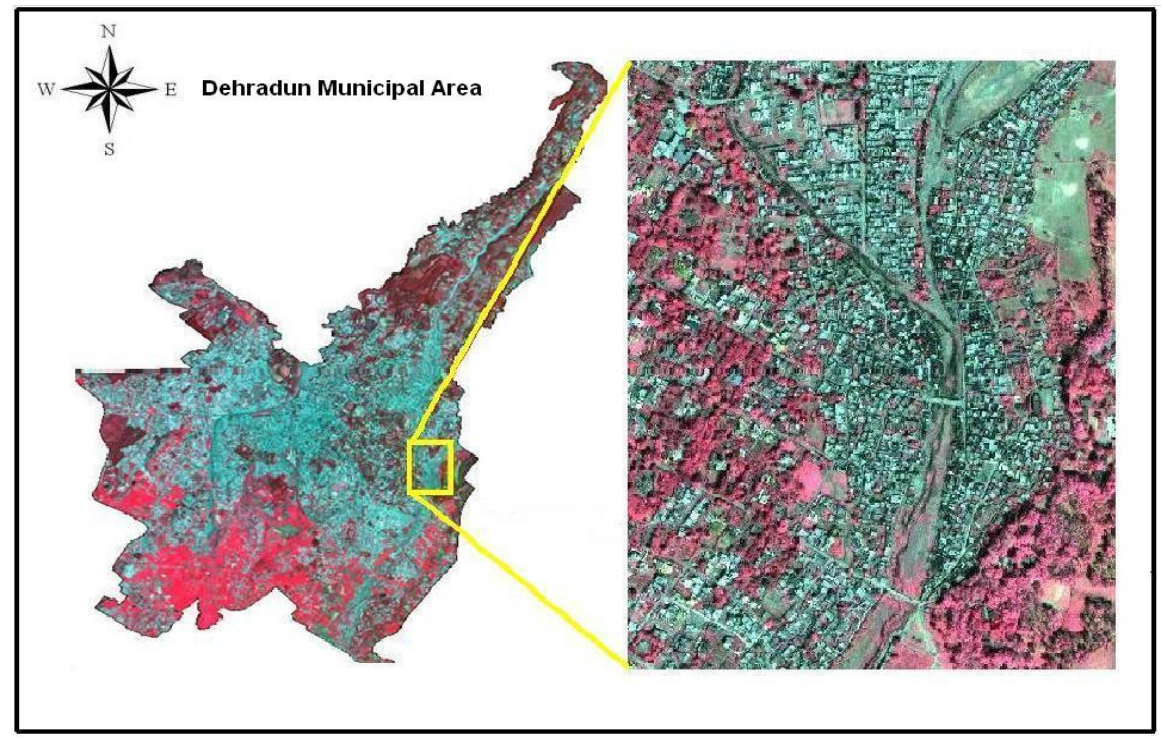

Fig.1. Location of Study Area around Rispana Rao River in Dehradun City

\subsection{Data Used}

In the study, IKONOS high resolution satellite merged image has been used to locate the household condition in slums. High resolution satellite data has been acquired on May 05, 2005 with projection UTM and datum WGS 84. Satellite had sun angle azimuth $135.46^{\circ}$ and elevation $71.27^{\circ}$ at the time of data acquisition. Thus, position of the sun with respect to north of the earth is towards south-east direction, which causes considerable small shadows of objects towards north-west direction. This means that a building that is $3 \mathrm{~m}$ high will cast a shadow of about $1.46 \mathrm{~m}$ long in a northwesterly direction. Since the sun angle is relatively higher from $45^{\circ}$, the shadows of the buildings tend to effectively delineate some detail, which is generally advantageous in increasing the apparent quality of the image. High resolution satellite data are highly valuable in the situation of complicated urban areas where somewhat little measurement and complex spatial patterns of the part (e.g. houses, streets and intra-urban start space) have restricted the usage of the low-resolution sensors. High resolution image therefore increase the quantity of information.

\subsection{Field Verification}

Field survey has been carried out for the validation of visual interpretation of IKONOS merged imagery as well as to collect the information. Detailed base map has been prepared at ward level. For this purpose, large scale colour print outs of the study area under examine were taken in the field. Field verification confirms about $70 \%$ reliability with this method.

\subsection{Survey in Slum Area}

Door to door survey via questionnaires for each and every household, has been performed to record the responses in a standard format. This survey has explored the information related to housing condition, water supply, electricity, primary schools, education, employment, and health services of the study area. 


\subsection{Mapping of Slum Area}

Visual interpretation of IKONOS merged imagery is very important part of methodology. Digitization and analysis of high resolution satellite imagery were carried out using software ARC GIS v 9.3. The detailed mapping with collected surveying data tables have been carried out to understand various problems associated with unplanned slum areas.

\section{Results and Discussion}

The findings of the study illustrate the slum condition using high resolution satellite imagery. This study has been surveyed total 1660 houses in the study area.

\subsection{Housing Condition}

Good Housing was the major problem of slum areas which creates a lot of problems for the development of sustainable life. About 571 houses (34.4\%) were in bad condition out of $1660(100 \%)$ surveyed houses (table 1and fig. 2).

\subsection{Availability of Water Supply}

Water availiability was another major problem of the study area and about $361(21.7 \%)$ houses out of $1660(100 \%)$ houses where water supply was not available (table 1and fig. 2).

\subsection{Availability of Electricity}

Electricity has become a basic need of the population. In the study area, out of total 1660 houses, 1648 houses $(99.2 \%)$ have electric supply whereas 13 houses $(0.78 \%)$ have not this facility (table 1 and fig. 2).

\subsection{Availability of Toilet}

The availability of toilets was another important indicator of the stage of sanitation. This in turn is reflected in the spread of several diseases especially those relating to the gastro- intestinal tract and skin etc. This facility was available in 1534 houses (92.4\%) and not available in 127 houses (07.65\%) shown in table 1 and fig. 2. This results in open defecation and consequently the spread of a host of diseases.

\subsection{Availability of Drainage}

In the study area, drainage facility was available in 1490 houses $(89.7 \%)$ but 170 houses $(10.3 \%)$ were not availing this facility (table 1 and fig. 2). Most of the drains were open, narrow and filled with solid waste.

\subsection{Availability of Primary Schools}

The study observed one another problem which was the primary schools in the slums. Most of the children under the age of 15 years are facing this problem. Some of these, 12 to 15 years old children were engaged in shops, Dhabas, industry, in building construction labour unit etc. Several factors conspire to deprive them of education. Their parents can't afford the costs associated with the nominally free government education and would have to go for an important part of household income if children attended schools instead of working for money. Slum children often work as domestic helpers, street vendors and beggars to supplement their family incomes. Number of primary schools was shown in fig. 2.

\subsection{Education Level}

The study has shown that 6764 people $(58.3 \%)$ of the respondents were literate with in total study area population 11600 and 4832 people (41.7\%) are not highly qualifies but they can generally read and write (table $1)$.

\subsection{Health Level}

This study has identified health related problems in slum areas. Most of the health related problems generates due to lack of employment, knowledge,education and hospital facilities. Most of the small children of slums play and live in open and dirty areas that affect their health in different ways like fever, malaria and other types of infections. If they don't find the proper health access and hospitality then their life is greatly compromised. 
Locating the Livelihood Problems for the Promotion of Sustainable Life in Slums of Dehradun,

Table 1: Livelihood Problems in Slums

\begin{tabular}{|c|c|c|c|}
\hline Problem/Facility & $\begin{array}{c}\text { Condition/ Not Available in House/ } \\
\text { Not High Qualified Persons }\end{array}$ & Percentage (\%) & ${\text { Area }\left(\mathbf{m}^{\mathbf{2}}\right)}$ \\
\hline Bad Houses & $571 / 1660$ House & $34.4 \%$ & 41286 \\
\hline Water & $361 / 1660$ House & $21.7 \%$ & 28074 \\
\hline Electricity & $13 / 1660$ House & $0.78 \%$ & 624 \\
\hline Toilet & $127 / 1660$ House & $7.65 \%$ & 7737 \\
\hline Drainage & $170 / 1660$ House & $10.3 \%$ & 11298 \\
\hline Education & $4832 / 11600$ Person & $41.7 \%$ & - \\
\hline
\end{tabular}
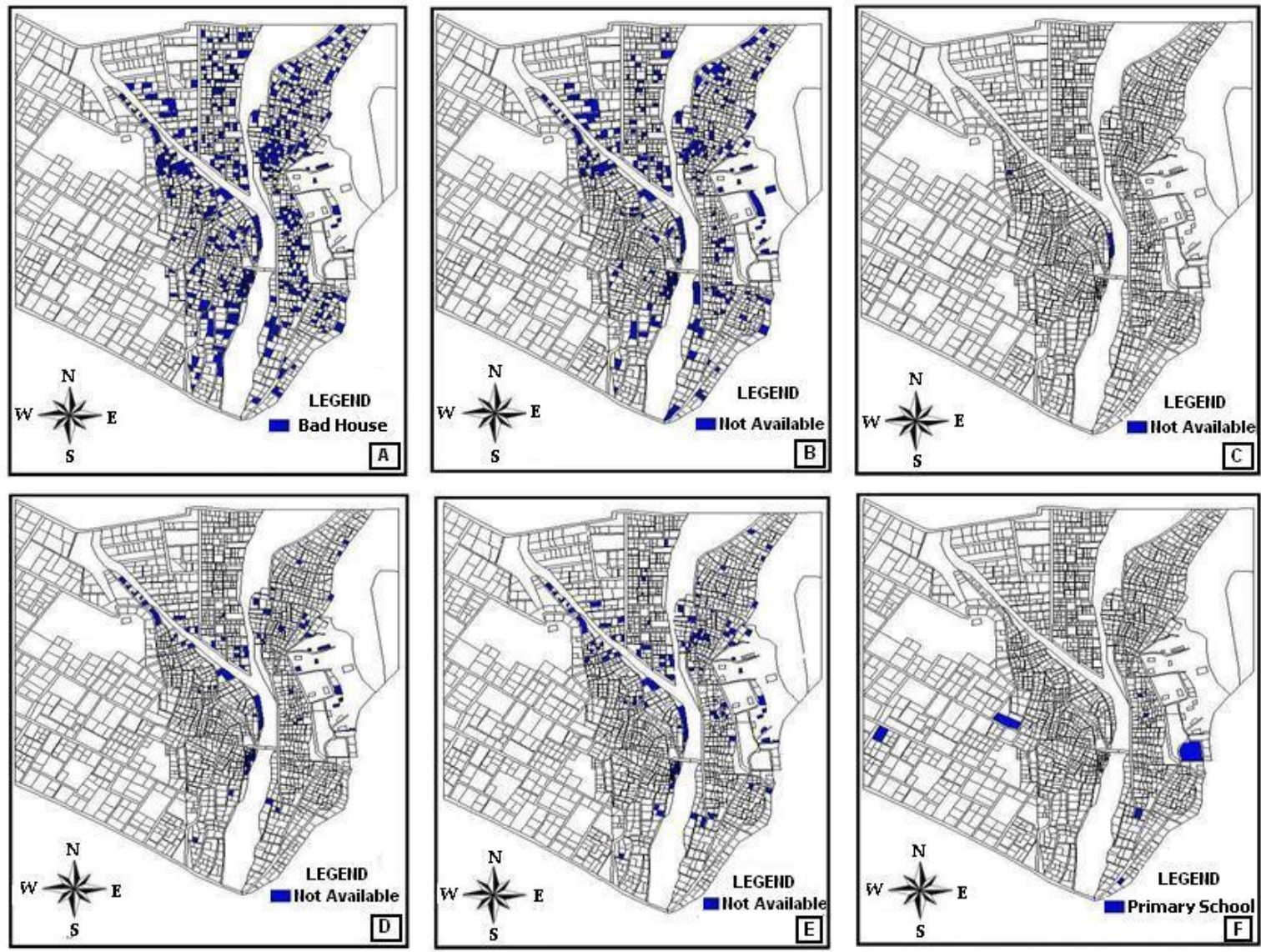

Fig.2. Locating Different Livelihood Problems, A: Housing Condition, B: Availability of Water Supply, C: Availability of Electricity, D: Availability of Toilet Facility, E: Availability of Drainage, and F: Location of Primary Schools

\section{Summary and Conclusions}

Urban poor living in slums and squatter settlements constitute the most rapidly growing segment of populations of developing countries. They are active agents of positive change and a slum or a cluster of families should be the planning and intervention point of programs. Mapping of slums and detailed assessment of available infrastructure helps to locating the livelihood problems for the promotion of sustainable life. Many of the people who live in the slums have always struggled to make a living and to find somewhere to live. So the natural reaction to the difficult environmental situations is acceptable.

The study was conducted to locating the livelihood problems for the promotion of sustainable life in slums of Dehradun. Some of the colonies have been identified in this study like Sanjay Colony, Bhagat Singh Colony, Shivpuri Colony, Purani Basti, and Mohini Road of the Dehradun which need appropriate intervention. 
A very small part of Dehradun city population lives in slums and face different problems which prevent their development. The estimated population of the inspected areas is approximately 11,600.

Most of the slums have developed in the periphery along the Rispana River. In this study we have observed that most of the slums face a lot of problems related to houses, water supply, electricity, primary schools, toilet, drainage, employment and health related issues.

\section{Acknowledgement}

Authors express their sincere thanks to Prof. D. P. Singh, Head, Department of Environmental Sciences, B.B.A.U, Lucknow, for providing the necessary facilities for conducting this study.

\section{References}

[1] A to Z of Housing Census; Summary Results on Houses, Household Amenities and Assets: Census of India, 2001.

[2] Baud, I., Sridharan, N. and Pfeffer, K. (2008). Mapping urban poverty for local governance in an Indian mega-city: The case of Delhi. Urban Studies, 45(7), 1385-1412. doi:10.1177/0042098008090679.

[3] Desai, A. R. and Devadas, S. (1990). Slums and urbanization. London: Sangam Books Limited.

[4] Global Development Research Centre (2003). Slums and squatter settlements: What is the difference? Retrieved November 20, 2013 from www. gdrc.org/ uem/squatters/slumsandsquatters.html

[5] Hofmann, P., Strobl, J., Blaschke, T. and Kux, H. (2008). Detecting informal settlements from Quickbird data in Rio De Janeiro using an object based approach. Object based Image Analysis, 23, 531-553

[6] Hasan, A. (2006). Orangi Pilot Project: The expansion of work beyond Orangi and the mapping of informal settlements and infrastructure. Environment and Urbanization, 18(2), 451-480. doi:10.1177/0956247806069626.

[7] Joshi, P., Sen, S., and Hobson, J. (2002). Experiences with surveying and mapping Pune and Sangli slums on a geographical information system (GIS). Environment and Urbanization, 14(2), 225-240. doi:10.1177/095624780201400218.

[8] Jain, S. (2007). Use of IKONOS satellite data to identify informal settlements in Dehradun, India. International Journal of Remote Sensing, 28(15), 3227-3233.

[9] Jain, S., Sokhi, B.S. and Sur, Ujjawal. (2005). Slum Identification using High- resolution Satellite Data, GIM International (Feature), pp- 60- 62.

[10] Kohli, Divyani., Sliuzas, Richard., Kerle and Norman, Stein. (2011). An ontology of slums for image-based classification. Computers, Environment and Urban Systems, 36, $154-163$.

[11] Khalifa, Marwa A. (2010). Redefining slums in Egypt: Unplanned versus unsafe areas, Habitat International xxx (2010), 1-10.

[12] Karanja, I. (2010). An enumeration and mapping of informal settlements in Kisumu, Kenya, implemented by their inhabitants Article. Environment and Urbanization, 22(1), 217-239. doi:10.1177/0956247809362642.

[13] Pitcher, H. M. (2009). The future of scenarios: issues in developing new climate change scenarios. Environmental Research Letters, 2(025002).

[14] Payne, G. (2005). Getting a head of the game: a twin-track approach to improving existing slums and reducing the need for future slums. Environment and Urbanization, 17(1), 135-146.

[15] Rajeshwari. (2006). Management of the Urban Environment Using Remote Sensing and Geographical Information Systems, J. Hum. Ecol., 20(4), 269-277.

[16] Shekhar, Sulochana. (2012). Modeling the probable growth of slums by using Geoinformatics, Indian J. Innovations Dev., Vol. 1, No. 8, 588- 598

[17] Sur, Ujjawal, Jain, S. and Sokhi B.S. (2005), High Resolution Satellite Image for Mapping and Physical Environment studies of Squatter settlement in Dehradun. Journal of Institute of Town Planners, India (ITPI), 2, 34-42.

[18] UN-HABITAT (2003b). The challenge of slums: Global report on human settlements 2003.

[19] United Nations. (2007). The millennium development goals report 2007. New York: United Nations.

[20] UN-Habitat. (2008). State of the world's cities 2008/2009 harmonious cities. London e Sterling, VA: United Nations Human Settlements Programme.

[21] UN-HABITAT (2010). State of world's cities 2010/2011: United Nations Human Settlements Programme (UN-HABITAT).

[22] WHO (1998). The World Health Report 1998: Life in the Twenty- First Century: A Vision for All. WHO, Geneva. 